\title{
Autoimmunity to Steroid-Producing Cells
}

\author{
Alberto Falorni and Stefania Marzotti \\ Department of Internal Medicine, Section of Internal Medicine and Endocrine and \\ Metabolic Sciences, University of Perugia \\ Italy
}

\section{Introduction}

Addison's disease, named after the English physician who provided its full description in 1855 , is the result of the destruction or impaired function of adrenocortical cells. Of the 11 cases described by Addison, 10 were likely subsequent to an infiltrative disease (the most common being the secondary localization of Mycobacterium tuberculosis to the adrenal gland) and 1 was clinically idiopathic (likely of an autoimmune origin, on the basis of the current knowledge of disease mechanisms). In recent years the ethiologic spectrum of the disease has considerably expanded to include genetic causes not present in the 11 cases described by Thomas Addison. Accordingly, the definition of primary adrenal insufficiency (PAI) appears today more correct. Nevertheless, Autoimmune Addison's Disease (AAD) and posttuberculosis Addison's disease are still adequate definitions according to the clinical characteristics of the cases described in 1855.

Prevalence of PAI is estimated at $120-160$ cases per million in western countries, corresponding to 1 case every 7,000-7,500 individuals (Laureti et al, 1999; Løvås et al, 2002). The clinical manifestations of the disease result from the glucorticoid, mineralcorticoid and androgen deficiency (Oelkers, 1996). In western countries and Japan, an autoimmune process is responsible for the destruction of the adrenocortical cells and for the clinical manifestations of PAI in around 70-90\% of cases (Betterle et al, 2002; Nomura et al, 1994).

AAD occurs frequently in concomitance with other organ-specific and non-organ-specific autoimmune diseases in the so-called autoimmune polyendocrine syndromes (APS). Since at least two-thirds of patients with AAD have one or more other manifestations of an ongoing autoimmune process against other endocrine glands or different tissues, AAD can be considered a paradigmatic disease for the study of endocrine autoimmunity. On the basis of the type of diseases present in the same patient, different APSs are recognized. APS 1 is caused by mutations of the AIRE (AutoImmune REgulator) gene, which is located on chromosome 21 (The Finnish-German APECED Consortium, 1997). This syndrome is characterized by the concomitant presence of at least two of three diseases: chronic mucocutaneous candidiasis, hypoparathyroidism and AAD. In first-degree relatives of APS1 patients a single disease manifestation is sufficient to formulate the diagnosis. No general agreement exists for the classification of the remaining APSs. Some authors discriminate APS 2, APS 3 and APS 4 according to the different combination of autoimmune diseases present in the same patients. With this classification, APS 2 would identify the association of clinical or pre-clinical AAD with thyroid autoimmune diseases 
and/or type 1 diabetes mellitus (T1DM). APS 3 would be the association of thyroid autoimmune diseases with other endocrine and non-endocrine autoimmune manifestations (with the exception of AAD) and APS 4 would include all other possible combinations. No sound pathophysiological and/or genetic background, however, supports this classification, as the different endocrine autoimmune diseases tend to share a common genetic background and the same subject that might be initially be classified as APS 3 or APS 4 would be reclassified as APS2 if clinical or subclinical signs of adrenal or thyroid autoimmunity occur at a later stage. Throughout this chapter we will then refer to APS 2 to include all combinations of AAD with other immuno-mediated diseases, different from hypoparathyroidism or chronic mucocutaneous candidiasis.

Most frequently AAD is associated with Hashimoto's thyroiditis or Graves's disease, one or the other being present in over $50 \%$ of patients with autoimmune adrenal insufficiency (Betterle et al, 2002; Nerup, 1974; Kong et al, 1994; Irvine et al, 1967, 1979; McHardy-Young et al, 1974; De Rosa et al, 1987; Papadopoulos et al, 1990; Kasperlik-Zaluska et al, 1991; Zelissen et al, 1995; Söderbergh et al, 1996; Neufeld et al, 1981). Atrophic gastritis is present in 20-25\% of AAD patients, while type 1 diabetes mellitus (T1DM) has been reported in $1-20 \%$ of addisonian patients (Betterle et al, 2002; Nerup, 1974; Kong et al, 1994; Irvine et al, 1967, 1979; McHardy-Young et al, 1974; De Rosa et al, 1987; Papadopoulos et al, 1990; Kasperlik-Zaluska et al, 1991; Zelissen et al, 1995; Söderbergh et al, 1996; Neufeld et al, 1981). Hypergonadotropic hypogonadism is present in $4.5-19 \%$ of AAD women. Other autoimmune diseases found associated with $\mathrm{AAD}$ at lower frequency include: vitiligo, alopecia, celiac disease, pernicious anemia, multiple sclerosis, inflammatory bowel disease, Sjögren's syndrome, chronic hepatitis and lymphocytic hypophysitis (Betterle et al, 2002; Nerup, 1974; Kong et al, 1994; Irvine et al, 1967, 1979; McHardy-Young et al, 1974; De Rosa et al, 1987; Papadopoulos et al, 1990; Kasperlik-Zaluska et al, 1991; Zelissen et al, 1995; Söderbergh et al, 1996; Neufeld et al, 1981).

\section{Adrenal autoimmunity}

The human adrenal autoimmune process is made evident by the apperance of circulating autoantibodies directed against the adrenal cortex or its components, which can be detected in the serum of affected individuals.

The first demonstration of adrenal cortex autoantibodies (ACA), detected by a complementfixation test in the sera from patients with AAD, was provided in 1957 (Anderson et al, 1957). The use of the indirect immunofluorescence (IIF) approach, introduced by Blizzard and Kyle, 1963, has subsequently enabled the development of more sensitive assays for the detection of ACA (Blizzard et al, 1963, 1967; Goudie et al, 1966; Andrada et al, 1968; Wuepper et al, 1969; Nerup, 1974; Irvine \& Barnes, 1974; Sotsiou et al, 1980; Elder et al, 1981; Papadopoulos et al, 1990). ACA have been detected in $40-75 \%$ patients with clinically idiopathic Addison's disease (Blizzard et al, 1963, 1967; Goudie et al, 1966; Andrada et al, 1968; Wuepper et al, 1969; Nerup, 1974; Irvine \& Barnes, 1974; Sotsiou et al, 1980; Elder et al, 1981; Stechmesser et al, 1985; Kosowicz et al, 1986; Papadopoulos et al, 1990). Differences in the substrate used for detection of autoantibodies (human vs. animal adrenals), in disease duration and in selection of patients are responsible for the high variability in ACA frequency in patients with PAI.

In spite of the very well known technical limitations, because of the relative simplicity of the assay and the high diagnostic sensitivity, ACA-IIF have represented the gold standard for 
adrenal autoantibody determination until the middle of the '90s. ACA react with cytoplasm autoantigen(s) of cells located in all three layers of the adrenal cortex. More recent studies have detected ACA in approximately $80 \%$ of patients with AAD, representing over $90 \%$ of patients with recent-onset disease and $79 \%$ with long-standing disease $(>2$ years of disease duration) (Betterle et al, 1999). ACA are more frequent in patients with APS1 or APS2 than in patients with isolated Addison's disease (Betterle et al, 1999).

Attempts to identify the molecular targets of ACA started during the 1980's, which led to the initial identification of a $55-\mathrm{kDa}$ autoantigen present in human adrenal microsomes (Furmaniak et al, 1988). Subsequent studies of the beginning of the 1990's have identified steroid-21-hydroxylase $(21 \mathrm{OH})$ as the main autoantigen target of ACA (Winqvist et al, 1992; Baumann-Antczak et al, 1992; Bednarek et al, 1992). Around the same time, steroid-17 $\alpha-$ hydroxylase $(17 \mathrm{OH})$ (Krohn et al, 1992) and P450 side chain cleavage (P450scc) enzyme (Winqvist et al, 1993) were identified as additional autoantigens.

The discovery of the molecular targets of ACA led to development of radiobinding assays with radiolabelled human autoantigen. The use of either in vitro translated $35 \mathrm{~S}-21 \mathrm{OH}$ (Falorni et al, 1995, 1997; Colls et al, 1995) or 125 I-21OH (Tanaka et al, 1997) has enabled the demonstration that $21 \mathrm{OH}$ autoantibodies $(21 \mathrm{OHAb})$ have a high diagnostic sensitivity and specificity for $\mathrm{AAD}$, being detected in over $95 \%$ of cases with clinically idiopathic adrenal insufficiency. The major epitopes recognised by human $21 \mathrm{OHAb}$ are located in the central and $\mathrm{COOH}$-terminal domains of the enzyme. In addition, naturally occurring mutations, associated with the development of congenital adrenal hyperplasia, inhibit the binding of human autoantibodies to recombinant $21 \mathrm{OH}$ (Chen et al, 1998, Nikoshkov et al, 1999). In vitro studies (Furmaniak et al, 1994) have shown that 21OHAb may inhibit the enzymatic activity of the autoantigen, but this finding has not been confirmed in vivo, during the natural history of the disease (Boscaro et al, 1996; Laureti et al, 2002).

Similarly to other organ-specific autoantibodies, 21OHAb have no major pathogenic role in the development of adrenal insufficiency, as they can be detected in approximately $1 / 200$ healthy subjects who do not necessarily progress towards clinical adrenal insufficiency. During pregnancy, 21OHAb cross the placental barrier, but do not determine any sign of clinical or pre-clinical adrenal insufficiency in the newborn (Betterle et al, 2004). Hence, $21 \mathrm{OHAb}$ are a highly senstive and specific immunological marker of the ongoing adrenal autoimmune process, but do not act as an effector of the destructive autoimmune process.

Our group has recently shown that $21 \mathrm{OHAb}$ are predominantly IgG1, with a minor expression of IgG2 and IgG4, which demonstrates a Th1-oriented type of immune response (Brozzetti et al, 2010a). However, approximately 10\% of AAD patients express IgG4$21 \mathrm{OHAb}$ in the absence of IgG1 (Brozzetti et al, 2010a). This type of IgG subclass selection reveals a more Th2-oriented type of activation. At present, it is still unclear whether this distinct subgroup of patients with a more Th2-oriented type of immune response represents a different population of AAD subjects or is the expression of a different stage of the natural history of the disease.

Although $17 \mathrm{OHAb}$ and $\mathrm{P} 450 \mathrm{sccAb}$ can be detected in a small fraction of patients with AAD, these markers are more frequently present in patients with APS 1 or in women with autoimmune oophoritis which causes autoimmune ovarian insufficiency (see paragraph on Ovarian Autoimmunity) (Betterle et al, 1999; Perniola et al, 2000; Falorni et al, 2002a).

Diagnosis of PAI is based on clinical ground and hormonal determination, but the ethiologic diagnosis of $\mathrm{AAD}$ requires detection of circulating $21 \mathrm{OHAb}$, by using a radiobinding assay. 
Autoantibody titer is also important, because the presence of low titre adrenal autoantibodies does not enable the unequivocal diagnosis of AAD in all cases (Falorni et al, 2004). ACA and 21OHAb have sporadically been found also in patients with unequivocal post-tuberculosis Addison's disease (Nomura et al, 1994; do Carmo Silva et al, 2000). A flowchart for the etiological classification of PAI, that takes into consideration immunological, biochemical and imaging data, has been developed by the Italian Addison Network (Falorni et al, 2004). Published data indicate that the diagnostic accuracy of the $21 \mathrm{OHAb}$ assay is higher than that of the ACA-IIF (Falorni et al, 2004), and 21OHAb is currently the gold standard for detection of adrenal autoantibodies. In the case of a simultaneous presence of both ACA and 21OHAb, the probability of an accurate diagnosis of AAD is higher than $99 \%$ (Falorni et al, 2004). All patients with AAD should undergo additional autoantibody analyses, such as thyroid autoantibodies, GAD autoantibodies (GADA), steroid-cell autoantibodies (StCA), 17OHAb, P450sccAb or parietal cell autoantibodies, as approximately two thirds of AAD patients show clinical or pre-clinical signs of another autoimmune disease. Autoimmune AAD can be diagnosed also in the presence of mediumhigh levels of either 21OHAb or ACA (Falorni et al, 2004). In the case of patients positive only for $21 \mathrm{OHAb}$ or ACA at low levels, as well as in autoantibody-negative subjects, adrenal imaging should be performed to exclude an infiltrative form of adrenal insufficiency (such as post-tuberculosis, sarcoidosis, mycosis or metastatic localization of non-adrenal tumours) (Falorni et al, 2004). In male patients negative for both adrenal autoantibody measurement and adrenal imaging analysis, determination of plasmatic very long chain fatty acids (VLCFA) must be performed to exclude X-linked adrenoleukodystrophy (ALD).

At present, no clear and standardised cut-off is available to discriminate between low and medium-high level autoantibody titers and worskhops for the standardization of adrenal autoantibody assays are strongly needed. In a first international serum exchange to compare the results of $21 \mathrm{OHAb}$ determination in four independent laboratories, a good positivenegative concordance was observed, but major discrepancies emerged in quantitation of autoantibody titre (Falorni et al, 2011). A European program for the standardization of $21 \mathrm{OHAb}$ assay is currently being organised, and is expected to be completed within 2012 .

Screening of subjects with endocrine autoimmune diseases for the presence of 21OHAb enables the identification of subjects with so-called preclinical $A A D$, which is characterised by the presence of adrenal autoantibodies in the absence of clinical signs of adrenal insufficiency and in the presence of normal basal cortisol concentrations. In patients with autoimmune diseases, 21OHAb can be detected in around 0.5-1.5\% T1DM patients, $0.5-1.5 \%$ patients with autoimmune thyroid diseases, $0.5-1.0 \%$ patients with vitiligo and in $4-8 \%$ women with primary ovarian insufficiency (Betterle et al, 2002). 21OHAb-positive individuals exhibit a variable degree of adrenal dysfunction that can be classified in four different stages (Betterle et al, 1988).

Stage 0 indicates the apperance of adrenal autoantibodies, as a sign of the ongoing adrenal autoimmune process. 21OHAb appears before ACA, and lasts longer than ACA, during the natural history of the disease.

Often the first dysfunction observed as a consequence of the progression of the autoimmune process is an initial increase of plasmatic renin activity (PRA), at a time when normal ACTH-cortisol axis response is still present (stage 1). In stage 2, an impaired response to the ACTH stimulation test is documented, while the final stage 3 represents the preclinical stage characterized by increased basal ACTH levels, along with the dysfunctions observed in stage 1 and 2 . 
No preventative therapy is yet available to delay or block the progressive destruction of adrenocortical cells in pre-clinical AAD. An Italian study has shown that an immunosuppressive therapy with high-dose corticosteroids for the treatment of Graves' ophthalmopathy had been able to revert a stage 2 pre-clinical AAD in a 21OHAb-positive individual (De Bellis et al, 1993). As a result of the treatment, disappearance of adrenal autoantibodies and normalization of both ACTH-cortisol and PRA-aldosterone axis function was observed and maintained for over 10 years at follow-up (De Bellis et al, 1993). However, the possibility to revert an advanced pre-clinical adrenal insufficiency by high-dose steroid immunosuppression has not yet been confirmed in other independent studies and it is not recommended for the sole purpose of preventing the progression towards clinical AAD.

Among the factors associated with progression towards clinical adrenal insufficiency are adrenal autoantibody levels that tend to increase during the progression of the adrenal dysfunction (Betterle et al, 1997).

Approximately $80 \%$ of patients with stage 0 and stage 1 do not progress to clinical AAD and may show a spontaneous remission of the pre-clinical dysfunction (Laureti et al, 1998). On the other hand, no such spontaneous remission seems to occur in patients with stage 2 and stage 3, in whom progression to clinical AAD is observed in over 95\% of cases. A matematical formula that takes into consideration all known factors influencing risk of progression towards clinical AAD has been generated (Coco et al, 2006).

In subjects positive for 21OHAb and/or ACA, an ACTH stimulation test discriminates between a potentially reversible and an irreversible stage of the pre-clinical dysfunction. It has been shown that the high-dose $250 \mu \mathrm{g}$ of synthetic ACTH used in the classical ACTH test (HDT) is supra-maximal and that as little as $1 \mu \mathrm{g}$ of synthetic ACTH can determine a maximal stimulation of the adrenocortical cells (Arvat et al, 2000). The low-dose test with 1 $\mu \mathrm{g}$ of ACTH (LDT) has a high diagnostic sensitivity and specificity for pre-clinical adrenal dysfunction and can substitute the classical high-dose test (Laureti et al, 2000, 2002). An ongoing European multicenter study is currently testing the diagnostic accuracy and the predictive value of a $0.5 \mu \mathrm{g}$ low-dose ACTH test.

Among the factors increasing significantly the risk of progression towards clinical adrenal insufficiency, in subjects with subclinical AAD, the most important are: male gender, presence of other concomitant autoimmune diseases, impaired response to the LDT and a high 21OHAb titer (Coco et al, 2006). HLA-DR3-DQ2, DR4-DQ8 and CTLA-4 gene polymorphism are significantly associated with appearance of $21 \mathrm{OHAb}$, but do not influence the natural history of the disease and do not predict future clinical adrenal insufficiency (Coco et al, 2006; Falorni et al, unpublished data). Homozygosity for MICA5.1 was found to increase significantly the risk of progression towards clinical adrenal insufficiency (Barker et al, 2005), but larger, prospective studies are needed to confirm this finding. Because of the high predictive value of $21 \mathrm{OHAb}$ for future AAD, which is higher than $30 \%$ at 10 years of follow-up, screening of patients with ongoing endocrine autoimmune diseases with this marker is recommended to identify subjects with pre-clinical adrenal insufficiency.

\section{Genetics of autoimmune adrenal insufficiency}

Autoimmune Regulator (AIRE) is the causative gene for APS1 (The Finnish-German APECED Consortium, 1997). The AIRE gene product, Aire, acts as a strong activator of transcription (Pitkänen et al, 2000, 2001; Björses et al, 2000). Over 60 disease-associated 
mutations of the AIRE gene have been so far identified. Many mutations are located in the homogeneously staining region (HSR) in the N-terminal end of the protein. Other mutations, such as C311Y, P326Q, L397fsX478 are located in the plant homeodomain zinc finger 1 and 2, while only a few mutations, such as G228W or R257X have been identified in the DNA binding motif (Bottomley et al, 2001). It has been reported that a kindred carrying the G228W variant presented with an autosomal dominant autoimmune phenotype manifesting predominantly with thyroidits and distinct from APS1 (Cetani et al, 2001). The generation of a G228W-knocking mouse model showed that this AIRE variant acts in a dominant-negative manner causing a unique autoimmune syndrome (Su et al, 2008).

Disease-associated AIRE mutations are highly conserved within defined geographical areas. The R257X is the most frequently found mutation in Northern Italy and in Finland, while 964del13 is the most common mutation in the UK. In Sardinia, R139X is the typical AIRE mutation found in APS 1 patients.

Outside APS1, AAD shares many predisposing genetic factors with other endocrine autoimmune diseases that are components of APS2, such as thyroid autoimmune diseases and T1DM, the major genetic markers associated with the diseases beeing located in the HLA region on chromosome 6 . The disease is strongly and positively associated with both HLADRB1*0301-DQA1*0501-DQB1*0201 (DR3-DQ2) and DRB1*04-DQA1*0301-DQB1*0302 (DR4DQ8) (Falorni et al, 2008). The HLA-DRB1*01-DQA1*01-DQB1*0501 and DRB1*13-DQA1*0103DQB1*0603 haplotypes are negatively associated with genetic risk for AAD. Several studies have shown that the association of HLA class II haplotypes is still highly significant in patients with isolated AAD and does not depend on the coexistence of other autoimmune disorders in the same patient. DRB1-*0404 was more frequent among DRB1*04-positive AAD patients from US (Yu et al, 1999) and Norway (Myhre et al, 2002) as compared to both DRB1*04-positive healthy control subjects and DRB1*04-positive T1DM patients. The DRB1*0401 subtype was strongly and positively associated with T1DM, but not with AAD (Yu et al, 1999; Myhre et al, 2002). However, an Italian study from our group (Gambelunghe et al, 2005) did not confirm this hypothesis. In that study (Gambelunghe et al, 2005), it was observed that no statistically different distribution of DRB1*0401 and DRB1*0404 was detectable among T1DM patients and AAD patients. On the other hand, it was observed that the DRB ${ }^{*} 0403$ subtype, which was already known to confer strong protection for T1DM, was absent among 56 DRB1*04-positive AAD patients, but present in $27 \%$ DRB1*04-positive healthy control subjects, thus conferring protection also for the development of AAD.

Other HLA genes contribute to the risk for AAD, among which the MHC class I chainrelated A (MICA) gene polymorphism. The MICA gene encodes for a ligand for an activating receptor (NKG2D) present on $\gamma \delta$ T cells, CD8+CD28- $\alpha \beta$ T cells, natural killer cells and CD4+CD28- $\alpha \beta$ T cells and is located within the HLA class III region. There are speculations that MICA gene polymorphism might influence affinity for the NKG2D receptor. AAD is strongly associated with the transmembrane MICA 5.1 allele, with odds ratio similar to those observed for HLA class II haplotypes (Gambelunghe et al, 1999; Park et al, 2002). MICA6 appears to be negatively associated with disease risk for AAD (Gambelunghe et al, 1999).

Though the association of MICA with AAD appears to be independent from that with HLA class II haplotypes, the strong linkage disequilibrium existing within the DRB1*03DQA1*0501-DQB1*0201-MICA5.1-HLA-B extended haplotype has so far limited the possibility to discriminate the relative contribution of each gene marker and further studies on large populations are needed to provide an answer to this specific question. 
Similarly to T1DM and other autoimmune diseases, the genetic background for AAD includes also other genes believed to modulate the function of the immune system. The CTLA-4 gene polymorphism and the PTPN22 gene polymorphism have been found to modulate genetic risk for AAD (Falorni et al, 2008; Skinningsrud et al, 2008a). A recent metanalysis of European studies has confirmed that the CTLA- 4 Ala 17 polymorphism is strongly associated with genetic risk for AAD, independentenly from the well known association with the polymorphism of HLA class II genes (Brozzetti et al, 2010b).

Two independent European studies have shown the association of the class II transactivator (CIITA) (also denominated MHC2TA) gene with AAD (Ghaderi et al, 2006; Skinningsrud et $a l, 2008 b)$. Modulation of the expression of HLA class II determinants in antigen-presenting cells may represent a critical factor in the activation and maintenance of the organ-specific autoimmune process and genetic factors that may influence such expression may have an important role on the pathogenesis of autoimmune diseases. The regulatory factor $X$ complex (RFX) and CIITA are essential and specific for activation of class II promoters (Durand et al, 1997; Masternak et al, 1998; Reith \& Mach, 2001; Nekrep et al, 2002). More specifically, the class II expression on antigen presenting cells is under the control of CIITA, that exhibits cell-specific, cytokine-inducible and differentiation-specific expression and is expressed in the same cells that express class II molecules, such as B cells, monocytes, dendritic cells and activated T cells. The genetic association of CIITA with AAD appears to be independent from that with HLA gene markers.

Other reported AAD genetic associations include the vitamin D receptor and the CYP27B1 (25-hydroxyvitamin D3-1 $\alpha$-hydroxylase) gene and the NACHT leucine-rich-repeat protein 1 (NALP1) gene (Magitta et al, 2009).

\section{Pathophysiology of AAD}

No model of spontaneous autoimmune primary adrenal insufficiency is yet available. Experimental autoimmune adrenalitis has been induced in mice, guinea pigs, rats and monkeys by injection of adrenal homogenates mixed with adjuvants (Betterle et al, 2002), with a resulting delayed type of hypersensitivity to adrenal antigens, rather than the induction of an adrenal autoimmune process. No conclusive data are yet available on the possibility of inducing an autoimmune reaction by injecting the major adrenal autoantigen 21-hydroxylase.

The current unavailability of a reliable animal model of spontaneous adrenal autoimmunity similar to the human disease, has so far limited the studies on the pathophysiology of AAD. Major efforts are being profused to develop an animal model of AAD that may prove useful for the understanding of the molecular mechanisms responsible for the human disease.

The effector cells of the autoimmune-mediated destruction of adrenocortical cells are thought to be T lymphocytes (Hayashi et al, 1989; Freeman \& Weetman, 1992). Nerup et al., 1969, 1970, showed that patients with autoimmune adrenal insufficiency have T cells reactive against fetal adrenal extracts or adrenal mitochondrial fraction. Subsequently, it was shown that patients with recent-onset AAD have an increased expression of circulating Ia-positive $\mathrm{T}$ cells when compared to healthy control subjects (Rabinowe et al, 1984). Freeman \& Weetman, 1992 were able to demonstrate $\mathrm{T}$ cell proliferation in response to stimulation with adrenal proteins fractionated according to molecular weight. Patients with autoimmune polyendocrine syndrome type II, but not individuals with isolated Addison's disease, seem to have $\mathrm{CD} 4{ }^{+} \mathrm{CD} 25^{+}$regulatory $\mathrm{T}$ cells with defective suppressive capacity (Kriegel et al, 2004; Coles et al, 2005). 
Although several studies support the hypothesis of a major role of cellular immunity in the autoimmune destruction of the adrenocortical cells in Addison's disease, little is known of the individual antigens recognised by autoreactive $\mathrm{T}$ cells. Husebye et al. immunized BALB/c and SJL mice with recombinant $21 \mathrm{OH}$ and showed a selective significant proliferative response of $\mathrm{T}$ cells from lymph nodes against the peptide $342-361$ of $21 \mathrm{OH}$ that corresponds to the substrate binding site of the enzyme (Husebye et al, 2006).

Among Th cell subtypes, two main subtypes, denominated Th1 and Th2, are recognized. AAD is thougth to result from an unbalance of Th1/Th2 responses with a predominance of Th1 activity. Chemokines produced at the site of inflammation participate by recruiting $\mathrm{T}$ cells and by sustaining the immune reaction (Rotondi et al, 2007). Th1 cells mainly express CXCR3 and are recruited at the site of inflammation by CXCL9, CXCL10 and CXCL11. Th2 cells express different chemokine receptors, such as CCR4 and CCR8, thus being recruited in target tissues by CCL17, CCL22 and CCL1. The existence of an important IFN- $\gamma$-mediated pathogenetic loop has been proposed for endocrine autoimmunity, as release of CXCR3binding chemokines is stimulated by IFN- $\gamma$ and, in turn, these chemokines recruit Th- 1 cells that produce IFN- $\gamma$ (Rotondi et al, 2007).

In one report concerning the role of serum CXCL10 in AAD, serum levels of CXCL10 were significantly increased in patients with either clinically evident or subclinical adrenal insufficiency, as compared to healthy control subjects (Rotondi et al, 2005). The absence of a gender-related effect in AAD, either isolated or occurring within APS-2, suggested that autoimmune adrenalitis by itself was responsible for the high circulating levels of CXCL10. In the same study (Rotondi et al, 2005), it was also shown that release of CXCL10 by primary cell cultures of human zona fasciculata cells (hZFC) was undetectable basally, but significantly induced by stimulation with IFN- $\gamma$ or IFN- $\gamma$ plus TNF- $\alpha$, while stimulation of hZFC with TNF- $\alpha$ alone was not able to induce chemokine secretion. Interestingly, increasing concentrations of hydrocortisone progressively and significantly inhibited IFN- $\gamma$ induced and IFN- $\gamma$ - plus TNF- $\alpha$-induced CXCL10 secretion (Rotondi et al, 2005).

The inhibitory effect of glucocorticoids on chemokine production is in line with their antiinflammatory and immunosuppressive actions. Glucocorticoids are able to suppress the production of several cytokines and chemokines by inhibiting the nuclear factor- $\mathrm{\kappa B}$ and by activating protein-1 transcription factor families (Karin, 1998).

More recently, increased serum levels of Th1-related chemokines CXCL10 and macrophage inflammatory proteins 1alpha (CCL3/MIP-1alpha) and of the Th2- related chemokine macrophage inflammatory proteins 1 beta (CCL4/MIP-1beta) were observed in patients with AAD, which confirms the role of these chemokines in the autoimmune pathology of adrenal gland through the recruitment in loco of Th1 and Th2 cells (Bellastella et al, 2011).

Based on the above described body of evidence, we can hypothesize that Th1 cells play a major pathogenetic role, while autoantibody production is a side effect with no pathogenic relevance. The decrease in Treg activity is probably one of the main mechanisms at the basis of the unbalanced activity of Th1 cells. The active role of the adrenocortical cells in modulating the autoimmune inflammation, by producing Th1-attracting chemokines and cortisol, should not be underestimated. Based on knowledge derived from studies on ovarian autoimmunity (Samy et al, 2005), it is likely that the continuous drainage of autoantigens to regional lymph nodes be essential to maintain an adequate activity of antiinflammatory Treg cells and that the reduced activity of Tregs and the unbalance Th1/Th2 ratio observed in human endocrine autoimmunity occur at the site of regional lymph nodes. 


\section{Ovarian autoimmunity}

Although it has been proposed that up to $30 \%$ of cases of primary ovarian insufficiency (POI) would have an autoimmune origin (Meskhi et al, 2006; Calongos et al, 2009), a more accurate estimate indicates that a documented ovarian autoimmune reaction is present in not more than $4-5 \%$ of women with ovarian insufficiency (Hoek et al, 1997; Bakalov et al, 2005).

Similarly to the study of adrenal autoimmunity, the unavailability of an animal model of spontaneous autoimmune oophoritis has limited the possibility to define the molecular mechanisms of immune-mediated ovarian insufficiency. The animal model of neonatal thymectomy has proven instrumental to unravel the critical role of $\mathrm{CD} 4{ }^{+} \mathrm{CD} 25^{+}$regulatory $\mathrm{T}$ (Treg) cells (Samy et al, 2006) in suppressing autoimmune processes in regional lymph nodes, under a continuous stimulation by autologous antigens (Samy et al, 2005). The ovarian autoantigen identified in the animal model of neonatal thymectomy is the ooplasmspecific MATER (Maternal Antigen That Embryo Requires) protein.

Immunization of mice with a peptide of inhibin alpha chain induced an initial increase in fertility, mediated by high serum levels of inhibin alpha neutralizing antibodies, that prevented inhibin-mediated downregulation of activin-induced FSH release (Altuntas et al, 2006). In a second, delayed phase, the activation of CD4+ T-cells resulted in a lymphocytic infiltration of the ovary that occurred in parallel with a progressive decrease in fertility and ovarian function (Altuntas et al, 2006).

However, it is still unclear to what extent these animal models are similar to human autoimmune POI.

Several lines of evidence support the autoimmune origin of a fraction of POI cases. Some autoimmune diseases are more frequent in women with POI than in the general population, and, conversely, POI occurs more frequently in women affected by some autoimmune diseases than in other women. Approximately 15\% of women with POI present with autoimmune thyroiditis (Hoek et al, 1997) and the frequency of POI is higher in women with T1DM than in the general population (Hoek et al, 1997). However, it must be noted that biochemical and/or ultrasound signs of thyroiditis can be detected in 10-15\% women in the general population and that the concomitant association of POI and thyroiditis or POI and T1DM in the same woman does not justify per se a diagnosis of "autoimmune POI". Surely more relevant is the association between POI and AAD (Betterle et al, 2002; Hoek et al, 1997; Falorni et al, 2002b). Approximately $4-8 \%$ of women with POI are positive for circulating adrenal autoantibodies, a frequency significantly higher than that expected in the general population $(<0.5 \%)$ (Betterle et al, 2002; Falorni et al, 2002b). On the other hand, $10-20 \%$ of women with AAD develop POI before the age of 40 years (Betterle et al, 2002).

The existence of ovarian autoantibodies was first shown in the 1960's in studies that used indirect immunofluorescence on cryostatic sections of adrenal, ovary, testis and placenta (Blizzard et al, 1967; Irvine \& Barnes, 1974). Subsequent studies have repeatedly confirmed the existence of ovarian autoantibodies in women with POI (Sotsiou et al, 1980; Elder et al, 1981; Ahonen et al, 1987; Betterle et al, 1993). Ovarian autoantibodies detected by indirect immunofluorescence cross-react with autoantigens expressed in other tissues, mainly the adrenal cortex, the testis and the placenta, which indicates that the autoantigen(s) recognized by these autoantibodies are not restricted to the ovary, but expressed also in other organs. Hence, a more correct definition of these autoantibodies is that of Steroid-Cell Autoantibodies (StCA). Interestingly, although all the tissue components are present in the 
ovarian cryostatic sections used for the autoantibody assay, the immunofluorescence pattern of StCA is restricted to the theca cells of the growing follicle with no staining of primary follicles or granulosa cells in secondary and tertiary follicles. The same autoantibodies stain specifically Leydig cells of the testis.

Although indirect immunofluorescence is still the most widely used method to detect ovarian autoantibodies in clinical practice, the accuracy of this method has been questioned, mostly because of a low diagnostic specificity (Novosad et al, 2003). Some of the autoantigens recognised by StCA have been identified as the steroidogenic enzymes $17 \alpha-$ hydroxylase (17OH) and side-chain cleavage (P450scc) (Chen et al, 1996; Perniola et al, 2000; Falorni et al, 2002b). The development of immunoradiometric assays, using in vitro translated recombinant human 35S-radiolabelled autoantigens, have enabled the estimate of the diagnostic sensitivity and specificity of $17 \mathrm{OHAb}$ and P450sccAb for autoimmune POI (Chen et al, 1996; Perniola et al, 2000; Falorni et al, 2002b).

$17 \mathrm{OHAb}$ and $\mathrm{P} 450 \mathrm{scc} \mathrm{Ab}$ are each present in 50 to $80 \%$ of women positive for StCA (Chen et al, 1996; Perniola et al, 2000; Falorni et al, 2002b). Over 90\% of StCA-positive women are positive for $17 \mathrm{OHAb}$ and/or $\mathrm{P} 450 \mathrm{sccAb}$, which is demonstrating that $17 \mathrm{OH}$ and $\mathrm{P} 450 \mathrm{scc}$ are major targets of StCA, but other autoantigens may also be recognized by a subset of StCA.

StCA, 17OHAb and/or P450sccAb can be detected almost exclusively in women with POI who are also positive for adrenal autoantibodies, most specifically $21 \mathrm{OHAb}$. The association of steroid-cell autoimmunity with adrenal autoimmunity is so strong that $21 \mathrm{OHAb}$ appear to be the marker at highest diagnostic sensitivity for autoimmune POI (Perniola et al, 2000; Falorni et al, 2002b, Bakalov et al, 2005). Since only less than $0.5 \%$ of women with POI can be found positive for StCA in the absence of 21OHAb, 17OHAb or P450sccAb, we can conclude that unequivocal biochemical signs of ovarian autoimmunity against steroidogenic enzymes are present almost exclusively in women with clinical or pre-clinical AAD.

Several studies have demonstrated that an autoimmune oophoritis can be found at ovarian biopsy only in women positive for ovarian and/or adrenal autoantibodies (Irvine, 1980; Gloor \& Hurlimann, 1984; Sedmak et al, 1987; Bannatyne et al, 1990; Hoek et al, 1997; Bakalov et al, 2005), thus confirming that steroidogenic cell autoantibodies identify women with an ongoing ovarian autoimmune process. On the other hand, in the absence of ovarian and adrenal autoantibodies, no histological sign of autoimmune infiltration can typically be detected at ovarian biopsy, even in women who present with other autoimmune diseases, such as thyroiditis, T1DM, inflammatory bowel disease or systemic lupus erithematosus. Accordingly, a classification of autoimmune POI cannot be based only on the presence of other autoimmune manifestations, in the absence of specific autoantibodies in the serum.

Autoimmune oophoritis is characterized by a selective mononuclear cell infiltration into the theca layer of large, antral follicles, with earlier stage follicles consistently free of lymphocytic infiltration (Hoek et al, 1997; Bakalov et al, 2005). This finding is in line with the selective staining of theca cells at the indirect immunofluorescence assay and confirms that the steroidogenic cell ovarian autoimmune process is mainly directed against theca cells.

The absence of steroidogenic cell autoantibodies does not exclude the possibility that other autoantibodies may be present and other autoimmune mechanisms may be active. Many other potential autoantigens, such as LH receptor (Moncayo et al, 1989), FSH receptor (Ryan \& Jones, 2004), zona pellucida (Kelkar et al, 2005), 82-86 kDa Ags and 52-63 kDa Ags (Wheatcroft et al, 1997) have been proposed as markers of ovarian autoimmunity, but the association of these autoantibodies with POI has not been confirmed (Anasti et al, 1995; 
Tonacchera et al, 2004). Only detection of autoantibodies against steroidogenic enzymes can, accordingly, ensure, at present, an accurate identification of women with autoimmune oophoritis. Using these autoantibody markers, autoimmunity accounts for approximately 4$5 \%$ of all POI cases.

Along with the decline of serum concentrations of estradiol, POI is typically characterized with a reduction in synthesis and secretion of inhibins (Petraglia et al, 1998) and antimüllerian hormone (AMH) (Méduri et al, 2007), as a result of the progressive decline in ovarian function. In an initial study of three women with autoimmune POI (Welt et al, 2005) this general paradigma was however questioned, as increased serum concentrations of inhibin B were detected. This initial finding was confirmed in a subsequent larger study (Tsigkou et al, 2008) that demonstrated increased levels of serum inhibin B and total inhibin in a group of 22 women with autoimmune POI, as compared to 71 women with idiopathic, non-autoimmune POI and 90 healthy fertile women. The results of these studies (Welt et al, 2005; Tsigkou et al, 2008) led to the formulation of a novel hypothesis of the pathophysiology of autoimmune POI. Differently from other forms of ovarian insufficiency, in which a general reduction of ovarian function can be observed, autoimmune POI is characterized by the selective autoimmune destruction of theca cells with preservation of granulosa cells that produce low amounts of estradiol because of lack of substrates. The subsequent increase in FSH levels stimulates viable granulosa cells that, in return, produce increased amounts of inhibins.

$\mathrm{AMH}$ levels have been found to be normal in women with hypogonadotrophic amenorrhea while they are very low or undetectable in women with physiological menopause or hypergonadotrophic amenorrhea (POI) (Méduri et al, 2007; La Marca et al, 2006; Knauff et al, 2009). AMH is exclusively produced by primary and pre-antral/small antral follicles, and the immunohistochemical findings of the absence of an inflammatory reaction around primary follicles (Hoek et al, 1997; Bakalov et al, 2005) provided a sound rationale to estimate AMH production in women with autoimmune POI. We recently documented normal serum AMH concentrations in two-thirds of women with recently diagnosed autoimmune POI (La Marca et al, 2009), which provides the first demonstration of the existence of a subgroup of women with POI with a preserved ovarian follicle pool for several years. Since AMH is the best biochemical marker of residual follicle pool, the results of our study (La Marca et al, 2009) are highly relevant for the future planning of clinical trials of immunotherapy aimed at preserving the residual functional tissue and/or delay the progression of the destructive ovarian autoimmune process in women with autoimmune POI.

\section{Conclusions}

Autoimmune Addison's disease is made evident by the apperance of circulating 21OHAb, the gold immune marker for the identification of subjects with an ongoing adrenal autoimmune process. The appearance of $21 \mathrm{OHAb}$ marks pre-clinical autoimmune Addison's disease, in asymptomatic subjects. In these individuals, the response to the ACTH-stimulation test enables the discrimination of an early, potentially reversible phase, from an irreversible phase of the disease.

POI affects around 1\% of women below the age of 40 years and the detection of steroid cell autoantibodies enables the identification of autoimmune cases. At present, only the detection of $21 \mathrm{OHAb}$ and $17 \mathrm{OHAb}$ or P450sccAb may accurately identify autoimmune cases of POI. 
Although autoantibodies are widely used in clinical practice, they have no pathogenic role for either $\mathrm{AAD}$ or POI and these diseases are thought to be the consequence of a T-cell mediated autoimmune destruction.

Substitutive therapy of either AAD or POI is not influenced by presence or absence of autoantibodies, but identification of autoimmune forms of these disease is nevertheless important. Approximately two thirds of AAD patients have at least another associated autoimmune disease, either clinical or pre-clinical. Accordingly, screening for other autoimmune disorders is mandatory in autoimmune AAD, but not strictly necessary in other forms of PAI. More importantly, autoimmune POI has a distinct pathophysiology which differs from that of other forms of ovarian insufficiency. Detection of steroid-cell autoantibodies enables the identification of subjects with an initially preserved follicle pool. No animal models of spontaneous steroid-cell autoimmunity are currently available, and there is strong need for the generation of such models that may enable the improvement of our understanding of the molecular mechanisms of these diseases.

During the next few years large multicentric studies are expected to be performed to identify subjects at high-risk for developing AAD and clinical trials are being planned with the aim of immunomodulate the adrenal autoimmune response and delay progression towards clinical AAD. The availability of novel immunological technologies will prove instrumental in the molecular characterization of the steroid cell autoantigens and peptides recognised by human autoreactive $\mathrm{T}$ cells responsible for the adrenocortical cell destruction. In addition, epidemiological studies are needed to provide novel insights on the role of putative environmental factors.

\section{References}

Ahonen P, Miettinen A, Perheentupa J. Adrenal and steroidal cell antibodies in patients with autoimmune polyglandular disease type I and risk of adrenocortical and ovarian failure. J Clin Endocrinol Metab 64:494-500 (1987).

Altuntas CZ, Johnson JM, Tuohy VK. Autoimmune targeted disruption of the pituitaryovarian axis causes premature ovarian failure. J Immunol 177:1988-1996 (2006).

Anasti JN, Flack MR, Froehlich J, Nelson LM. The use of human recombinant gonadotropin receptors to search for immunoglobulin G-mediated premature ovarian failure. $J$ Clin Endocrinol Metab 80:824-828 (1995).

Anderson JR, Goudie RB, Gray KG, Timbury GC. Autoantibodies in Addison's disease. Lancet 1:1123-1124 (1957).

Andrada JA, Bigazzi PL, Andrada E, Milgrom F, Witebsky E. Serological investigation on Addison's disease. Clin Sci 206:1535-1541 (1968).

Arvat E, Di Vito L, Laffranco F et al. Stimulatory effect of adrenocorticotropin on cortisol, aldosterone, and dehydroepiandrosterone secretion in normal humans: doseresponse study. J Clin Endocrinol Metab 88:3141-3146 (2000).

Bakalov VK, Anasti JN, Calis KA, et al. Autoimmune oophoritis as a mechanism of follicular dysfunction in women with 46,XX spontaneous premature ovarian failure. Fertil Steril 84:958-965 (2005).

Bannatyne P, Russell P, Shearman RP. Autoimmune oöphoritis: a clinicopathologic assessment of 12 cases. Int J Gynaecol Pathol 9:191-207 (1990) 
Barker JM, Ide A, Hostetler C et al. Endocrine and immunogenetic testing in individuals with type 1 diabetes and 21-hydroxylase autoantibodies: Addison's disease in a high-risk population. J Clin Endocrinol Metab 90:128-134 (2005).

Baumann-Antczak A, Wedlock N, Bednarek J et al. Autoimmune Addison's disease and 21hydroxylase. Lancet 340:429-430 (1992).

Bednarek J, Furmaniak J, Wedlock N, et al. Steroid 21-hydroxylase is a major autoantigen involved in adult onset autoimmune Addison's disease. FEBS Lett 309:51-55 (1992).

Bellastella G, Rotondi M, Pane E, et al. Simultaneous evaluation of the circulating levels of both Th1 and Th2 chemokines in patients with Autoimmune Addison's Disease. J Endocrinol Invest (2011), in press

Betterle C, Scalici C, Presotto F, et al. The natural history of adrenal function in autoimmune patients with adrenal autoantibodies. J Endocrinol 117:467-475 (1988).

Betterle C, Rossi A, Dalla Pria S, et al. Premature ovarian failure: autoimmunity and natural history. Clin Endocrinol (Oxf) 39:53-43 (1993).

Betterle C, Volpato M, Rees-Smith B et al. I. Adrenal cortex and steroid 21-hydroxylase autoantibodies in adult patients with organ-specific autoimmune diseases: markers of low progression to clinical Addison's disease. J Clin Endocrinol Metab 82:932-938 (1997).

Betterle C, Volpato M, Pedini B, Chen S, Rees-Smith B, Furmaniak J.Adrenal-cortex autoantibodies (ACA) and steroid-producing cells autoantibodies (StCA) in patients with Addison's disease: comparison between immunofluorescence and immunoprecipitation assays. J Clin Endocrinol Metab 84:618-622 (1999).

Betterle C, Dal Pra C, Mantero F, Zanchetta R. Autoimmune adrenal insufficiency and autoimmune polyendocrine syndromes: autoantibodies, autoantigens, and their applicability in diagnosis and disease prediction. Endocr Rev 23:327-364 (2002).

Betterle C, Dal Pra C, Pedini B, et al. Assessment of adrenocortical function and autoantibodies in a baby born to a mother with autoimmune polyglandular syndrome Type 2. J Endocrinol Invest 27:618-21 (2004).

Björses P, Halonen M, Palvimo JJ et al. Mutations in the AIRE gene:effects on subcellular location and transactivation function of the autoimmune polyendocrinopathycandidiasis-ectodermal dystrophy protein. Am J Hum Genet 66:378-392 (2000)

Blizzard RM, Kyle M. Studies of the adrenal antigens and autoantibodies in Addison's disease. J Clin Invest 42:1653-1660 (1963).

Blizzard RM, Chee D, Davis W. The incidence of adrenal and other autoantibodies in the sera of patients with idiopathic adrenal insufficiency (Addison's disease). Clin Exp Immunol 2:19-30 (1967).

Boscaro M, Betterle C, Volpato M, et al. Hormonal responses during various phases of autoimmune adrenal failure: no evidence for 21-hydroxylase enzyme activity block in vivo. J Clin Endocrinol Metab 81:2801-2804 (1996).

Bottomley MJ, Collard MW, Huggenvik JI et al. The SAND domain structure defines a novel DNA-binding fold in transcriptional regulation. Nat Struct Biol 8:626-33 (2001).

Brozzetti A, Marzotti S, La Torre D, et al. Autoantibody responses in autoimmune ovarian insufficiency and in Addison disease are IgG1-dominated and suggest a 
predominant, but not exclusive, Th1 type of response. Eur. J. Endocrinol 163:309-317 (2010a).

Brozzetti A, Marzotti S, Tortoioli C, et al. Cytotoxic T Lymphocyte Antigen-4 Ala17 polymorphism is a genetic marker of autoimmune adrenal insufficiency: Italian association study and meta-analysis of European studies. Eur. J.Endocrinology 162:361-9 (2010b).

Calongos G, Hasegawa A, Komori S, Koyama K. Harmful effects of anti-zona pellucida antibodies in folliculogenesis, oogenesis, and fertilization. J. Reprod. Immunol. 79:148-155 (2009).

Cetani F, Barbesino G, Borsari S et al. A novel mutation of the autoimmune regulator gene in an Italian kindred with autoimmune polyendocrinopathy-candidiasis ectodermal dystrophy, acting in a dominant fashion and strongly cosegregating with hypothyroid autoimmune thyroiditis. J. Clin. Endocrinol. Metab. 86:4747-4752 (2001).

Chen S, Sawicka J, Betterle C, et al. Autoantibodies to steroidogenic enzymes in autoimmune polyglandular syndrome, Addison's disease and premature ovarian failure. J Clin Endocrinol Metab 81:1871-1876 (1996).

Chen S, Sawicka J, Prentice L, et al. Analysis of autoantibody epitopes on steroid 21hydroxylase $(21-\mathrm{OH})$ using a panel of monoclonal antibodies. J Clin Endocrinol Metab 83:2977-2986 (1998).

Coco G, Dal Pra C, Presotto F, et al. Estimated risk for developing autoimmune Addison's disease in patients with adrenal cortex autoantibodies. J Clin Endocrinol Metab 91:1637-1645 (2006).

Coles AJ, Thompson S, Cox AL, Curran S, Gurnell EM, Chatterjee VK. Dehydroepiandrosterone replacement in patients with Addison's disease has a bimodal effect on regulatory (CD4+CD25hi and CD4+FoxP3+) T cells. Eur J Immunol. 35:3694-3703 (2005).

Colls J, Betterle C, Volpato M, Prentice L, Smith BR, Furmaniak J. Immunoprecipitation assay for autoantibodies to steroid 21-hydroxylase in autoimmune adrenal diseases. Clin Chem 41:375-380 (1995).

De Bellis A, Bizzarro A, Rossi R, et al. Remission of subclinical adrenocortical failure in subjects with adrenal autoantibodies. J Clin Endocrinol Metab 76:1002-1007 (1993).

De Rosa G, Corsello SM, Cecchini L, Della Casa S, Testa A. A clinical study of Addison's disease. Exp Clin Endocrinol 90:232-242 (1987).

do Carmo Silva R, Kater CE, Dib SA, et al. Autoantibodies against recombinant human steroidogenic enzyme 21-hydroxylase, side-chain cleavage and $17 \alpha$-hydroxylase in Addison's disease and autoimmune polyendocrine syndrome type III. Eur J Endocrinol 142:187-194 (2000).

Durand B, Sperisen P, Emery P, Barras E, Zufferey M, Mach B, Reith W. RFXAP, a novel subunit of the RFX DNA binding complex is mutated in MHC class II deficiency. EMBO J 16: 1045-1055 (1997).

Elder M, Maclaren N, Riley W. Gonadal autoantibodies in patients with hypogonadism and/or Addison disease. J Clin Endocrinol Metab 52:1137-1142 (1981). 
Falorni A, Nikoshkov A, Laureti S, et al. High diagnostic accuracy for idiopathic Addison's disease with a sensitive radiobinding assay for autoantibodies against recombinat human 21-hydroxylase. J Clin Endocrinol Metab 80:2752-2755 (1995).

Falorni A, Laureti S, Nikoshkov A, et al. 21-hydroxylase autoantibodies in adult patients with endocrine autoimmune diseases are highly specific for Addison's disease. Clin. Exper. Immunol. 107:341-345 (1997).

Falorni A, Laureti S, Candeloro P, et al. Steroid-cell autoantibodies are preferentially expressed in women with premature ovarian failure who have adrenal autoimmunity. Fertility \& Sterility 78:270-279 (2002a).

Falorni A, Laureti S, Santeusanio F. Autoantibodies in autoimmune polyendocrine syndrome type II. Endocrinol.Metab.Clin.N.Am. 31:369-389 (2002b).

Falorni A, Laureti S, De Bellis A, et al. Italian Addison Network Study: Update of diagnostic criteria for the etiological classification of primary adrenal insufficiency. J Clin Endocrinol Metab 89:1598-1604 (2004).

Falorni A, Brozzetti A, La Torre D, Tortoioli C, Gambelunghe G. The association of genetic polymorphisms and autoimmune Addison's disease. Expert Review of Clinical Immunology 4:441-456 (2008).

Falorni A, Chen S, Zanchetta $\mathrm{R}$ et al. Measuring adrenal autoantibody response: interlaboratory concordance in the first international serum exchange for the determination of 21-hydroxylase autoantibodies. Clin Immunol (2011), in press, doi: 10.1016/j.clim.2011.04.012

Freeman M, Weetman AP. T and B cell reactivity to adrenal antigens in autoimmune Addison's disease. Clin Exp Immunol 88:275-279 (1992).

Furmaniak J, Talbot D, Reinwein D, Benker G, Creagh FM, Smith B. Immunoprecipitation of human adrenal microsomal antigen. FEBS Lett 232:25-28 (1988).

Furmaniak J, Kominami S, Asawa T, Wedlock N, Colls J, Rees-Smith B. Autoimmune Addison's disease. Evidence for a role of steroid 21-hydroxylase autoantibodies in adrenal insufficiency. J Clin Endocrinol Metab 79:1517-1521 (1994).

Gambelunghe G, Falorni A, Ghaderi M et al. Microsatellite polymorphism of the MHC class I chain-related (MIC-A and MIC-B) genes marks the risk for autoimmune Addison's disease. J Clin Endocrinol Metab 84:3701-3707 (1999).

Gambelunghe G, Kockum I, Bini V et al. Retrovirus-like long terminal repeat DQ-LTR13 and genetic susceptibility to type 1 diabetes mellitus and autoimmune Addison's disease. Diabetes 54:900-905 (2005).

Ghaderi M, Gambelunghe G, Tortoioli C et al. MHC2TA single nucleotide polymorphism and genetic risk for autoimmune adrenal insufficiency. J Clin Endocrinol Metab 91:4107-4111 (2006).

Gloor E, Hurlimann J. Autoimmune oöphoritis. Am J Clin Pathol 81:105-109 (1984).

Goudie RB, Anderson JR, Gray KK, Whyte WG 1966 Autoantibodies in Addison's disease. Lancet 1:1173-1176 (1966).

Hayashi Y, Hiyoshi T, Takemura T, Kurashima C, Hirokawa K. Focal lymphocytic infiltration in the adrenal cortex of the elderly: immunohistological analysis of infiltrating lymphocytes. Clin Exp Immunol 77:101-105 (1989). 
Hoek A, Schoemaker J, Drexhage HA. Premature ovarian failure and ovarian autoimmunity. Endocr Rev 18:107-134 (1997).

Husebye ES, Bratland E, Bredholt G, Fridkin M, Dayan M, Mozes E. The substrate-binding domain of 21-hydroxylase, the main autoantigen in autoimmune Addison's disease, is an immunodminant T cell epitope. Endocrinology 147:2411-2416 (2006).

Irvine WJ, Stewart AG, Scarth L. A clinical and immunological study of adrenocortical insufficiency (Addison's disease). Clin Exp Immunol 2:31-69 (1967).

Irvine WJ, Barnes EW. Addison's disease and associated conditions: with particular references to premature ovarian failure, diabetes mellitus and hypoparathyroidism. In: Gell PH, Coombs RRA, Lachman P, eds. Clinical aspects of immunology. Oxford, UK: Blackwell; 1301-1354 (1974).

Irvine WJ, Toft AD, Feek CM. Addison's disease. In: James VHT, ed. The adrenal gland. New York: Raven Press; 131-164 (1979).

Irvine WJ. Autoimmunity in endocrine disease. Recent Prog Horm Res 36:509-556 (1980)

Karin M. New twists in gene regulation by glucocorticoid receptor: is DNA binding dispensable? Cell 93:487-490 (1998).

Kasperlik-Zaluska AA, Migdalska B, Czarnocka B, Drac-Kaniewska J, Niegowska E, Czech W. Association of Addison's disease with autoimmune disorders-a long-term observation of 180 patients. Postgrad Med J 67:984-987 (1991).

Kelkar RL, Meherji PK, Kadam SS, Gupta SK, Nandedkar TD. Circulating autoantibodies against the zona pellucida and thyroid microsomal antigen in women with premature ovarian failure. J Repr Immunol 66:53-67 (2005).

Knauff EAH, Eijkemans MJC, Lambalk CB, et al. Anti-müllerian hormone, inhibin B, and antral follicle count in young women with ovarian failure. J Clin Endocrinol Metab 94:786-792 (2009).

Kong MF, Jeffcoate W. Eighty-six cases of Addison's disease. Clin Endocrinol (Oxf) 41:757761 (1994).

Kosowicz J, Gryczynska M, Bottazzo GF. A radioimmunoassay for the detection of adrenal autoantibodies. Clin Exp Immunol 63:671-679 (1986).

Kriegel MA, Lohmann T, Gabler C, Blank N, Kalden JR, Lorenz HM. Defective suppressor function of human CD4+ CD25+ regulatory T cells in autoimmune polyglandular syndrome type II. J Exp Med 199:1285-1291 (2004).

Krohn K, Uibo R, Aavik E, Peterson P, Savilahti K. Identification by molecular cloning of an autoantigen associated with Addison's disease as steroid $17 \alpha$-hydroxylase. Lancet 339:770-773 (1992).

La Marca A, Pati M, Orvieto R, Stabile G, Carducci Artenisio A, Volpe A. Serum AntiMullerian Hormone levels in women with secondary amenorrhea. Fertil Steril 85:1547-1549 (2006).

La Marca A, Marzotti S, Brozzetti A, et al. Primary ovarian insufficiency due to steroidogenic cell autoimmunity is associated with preserved pool of functioning follicles. J Clin Endocrinol Metab 94:3816-3823 (2009).

Laureti S, De Bellis A, Muccitelli VI, et al. Levels of adrenocortical autoantibodies correlate with the degree of adrenal dysfunction in subjects with preclinical Addison's disease. J Clin Endocrinol Metab 83:3507-3511 (1998). 
Laureti S, Vecchi L, Santeusanio F, Falorni A. Is the prevalence of Addison's disease underestimated? J Clin Endocrinol Metab 84:1762 (1999)

Laureti S, Arvat E, Candeloro P, et al. Low dose $(1 \mu \mathrm{g})$ ACTH test in the evaluation of adrenal dysfunction in pre-clinical Addison's disease. Clin Endocrinol (Oxf) 53:107115 (2000).

Laureti S, Candeloro P, Aglietti MC, et al. Dehydroepiandrosterone, 17 $\alpha$ hydroxyprogesterone and aldosterone responses to the low-dose $(1 \mu \mathrm{g}) \mathrm{ACTH}$ test in subjects with preclinical adrenal autoimmunity. Clin Endocrinol (Oxf) 57:677-683 (2002).

Løvås K, Husebye ES. High prevalence and increasing incidence of Addison's disease in western Norway. Clin Endocrinol (Oxf) 56:787-791 (2002)

Magitta NF, Bøe Wolff AS, Johansson S et al. A coding polymorphism in NALP1 confers risk for autoimmune Addison's disease and type 1 diabetes. Genes Immun. 10:120-124 (2009).

Masternak K, Barras E, Zufferey $\mathrm{M}$ et al. A gene encoding a novel RFX-associated transactivator is mutated in the majority of MHC class II deficiency patients. Nature Gen 20:273-277 (1998).

McHardy-Young S, Lessof MH, Maisey MN. Serum TSH and thyroid studies in Addison's disease. Clin Endocrinol (Oxf) 1:45-56 (1974).

Méduri G, Massin N, Guibourdenche J, et al. Serum anti-Müllerian hormone expression in women with premature ovarian failure. Hum Reprod 22:117-123 (2007).

Meskhi A, Seif MW. Premature ovarian failure. Curr. Opin. Obstet. Gynecol. 18:418-426 (2006).

Moncayo H, Moncayo R, Benz R, Wolf A, Lauritzen C. Ovarian failure and autoimmunity. Detection of autoantibodies directed against both the unoccupied luteinizing hormone/human chorionic gonadotropin receptor and the hormonereceptor complex of bovine corpus luteum. J Clin Invest 84:1857-1865 (1989).

Myhre AG, Undlien DE, Løvås $\mathrm{K}$ et al. Autoimmune adrenocortical failure in Norway autoantibodies and human leukocyte antigen class II associations related to clinical features. J Clin Endocrinol Metab 87:618-623 (2002).

Nekrep N, Jabrane-Ferrat N, Wolf HM, Eibl MM, Geyer M, Peterlin BM. Mutation in a winged-helix DNA-binding motif causes atypical bare lympocyte syndrome. Nature Immunol. 3:1075-1081 (2002).

Nerup J, Andersen V, Bendixen G. Anti-adrenal, cellular hypersensitivity in Addison's disease. Clin Exp Immunol 4:355-363 (1969).

Nerup J, Andersen V, Bendixen G. Anti-adrenal, cellular hypersensitivity in Addison's disease. IV. In vivo and in vitro investigations on the mitochondrial fraction. Clin Exp Immunol 6:733-739 (1970).

Nerup J. Addison's disease-clinical studies. A report of 108 cases. Acta Endocrinol (Copenh) 76:127-141 (1974).

Neufeld M, MacLaren NK, Blizzard RM. Two types of autoimmune Addison's disease associated with different polyglandular autoimmune (PGA) syndromes. Medicine (Baltimore) 60: 355-362 (1981).

Nikoshkov A, Falorni A, Lajic S, et al. A conformation-dependent epitope in Addison's disease and other endocrinological autoimmune diseases maps to a carboxyl- 
terminal functional domain of human steroid 21-hydroxylase. J Immunol 162:24222426 (1999).

Nomura K, Depura H, Saruta T. Addison's disease in Japan: characteristics and changes revealed in a nationwide survey. Intern Med 33:602-606 (1994).

Novosad JA, Kalantaridou SN, Tong ZB, Nelson LM. Ovarian antibodies as detected by indirect immunofluorescence are unreliable in the diagnosis of autoimmune premature ovarian failure: a controlled evaluation. BMC Womens Health 3:2 (2003)

Oelkers W. Adrenal insufficiency. N Engl J Med 335:1206-1212 (1996)

Papadopoulos KI, Hallengren B. Polyglandular autoimmune syndrome type II in patients with idiopathic Addison's disease. Acta Endocrinol (Copenh) 122:472-478 (1990).

Park YS, Sanjeevi CB, Robles D et al. Additional association of intra-MHC genes, MICA and D6S273, with Addison's disease. Tissue Antigens 60:155-163 (2002).

Perniola R, Falorni A, Clemente MG, Forini F, Accogli E, Lobreglio G. Organ-specific and non-organ-specific autoantibodies in children and young adults with autoimmune polyendocrinopathy-candidiasis-ectodermal dystrophy (APECED). Eur J Endocrinol 143:497-503 (2000).

Petraglia F, Hartmann B, Luisi S, et al. Low levels of serum inhibin A and inhibin B in women with hypergonadotropic amenhorrea and evidence of high levels of activin A in women with hypothalamic amenhorrea. Fertil Steril 70:907-912 (1998).

Pitkänen J, Doucas V, Sternsdorf $\mathrm{T}$ et al. The autoimmune regulator protein has transcriptional transactivating properties and interacts with the common coactivator CREB-binding protein. J Biol Chem 275:16802-16809 (2000).

Pitkänen J, Vähämurto $\mathrm{P}, \mathrm{Krohn} \mathrm{K}$ et al. Subcellular localization of the autoimmune regulator protein. characterization of nuclear targeting and transcriptional activation domain. J Biol Chem 276:19597-19602 (2001).

Rabinowe SL, Jackson RA, Dluhy RG, Williams GH. Ia-positive T lymphocytes in recently diagnosed idiopathic Addison's disease. Am J Med 77:597-601 (1984).

Reith W, Mach B. The bare lymphocyte syndrome and the regulation of mhc expression. Annu. Rev. Immunol. 19:331-373 (2001).

Rotondi M, Falorni A, De Bellis A et al. Elevated serum interferon- $\gamma$-inducible chemokine$10 /$ CXC chemokine ligand-10 in autoimmune primary adrenal insufficiency and in vitro expression in human adrenal cells primary cultures after stimulation with proinflammatory cytokines. J Clin Endocrinol Metab 90:2357-2363 (2005).

Rotondi M, Chiovato L, Romagnani S, Serio M, Romagnani P. Role of chemokines in endocrine autoimmune diseases. Endocrine Rev 28:492-520 (2007).

Ryan MM, Jones HR Jr. Myasthenia gravis and premature ovarian failure. Muscle Nerve 30:231-233 (2004).

Samy ET, Parker LA, Sharp CP, Tung KSK. Continuous control of autoimmune disease by antigen-dependent polyclonal CD4+CD25+ regulatory T cells in the regional lymph node. J Exp Med 202:771-781 (2005).

Samy ET, Setiady YY, Ohno K, Pramoonjago P, Sharp C, Tung KSK. The role of physiological self-antigen in the acquisition and maintenance of regulatory T-cell function. Immunol Rev 212:170-84 (2006). 
Sedmak DD, Hart WR, Tubbs RR. Autoimmune oöphoritis: a histopathologic study involved ovaries with immunologic characterization of the mononuclear cell infiltrate. Int J Gynecol Pathol 6:73-81 (1987).

Skinningsrud B, Husebye ES, Gervin K et al. Mutation screening of PTPN22: association of the 1858T-allele with Addison's disease. Eur J Hum Genet. 16:977-982 (2008a).

Skinningsrud B, Husebye E, Pearce SH et al. Polymorphisms in CLEC16A and CIITA at 16 p13 are associated with primary adrenal insufficiency. J Clin Endocrinol Metab 93:3310-3317 (2008b).

Sotsiou F, Bottazzo GF, Doniach D. Immunofluorescence studies on autoantibodies to steroid-producing cells, and to germline cells in endocrine disease and infertility. Clin Exp Immunol 39:97-111 (1980).

Stechmesser E, Scherbaum WA, Grossman T, Berg PA. An ELISA method for the detection of autoantibodies to adrenal cortex. J Immunol Methods 80:67-76 (1985).

Su MA, Giang K, Zumer K et al. Mechanisms of an autoimmune syndrome in mice caused by a dominant mutation in Aire. J Clin Invest 118:1712-1726 (2008).

Söderbergh A, Winqvist O, Norheim I, et al. Adrenal autoantibodies and organ-specific autoimmunity in Addison disease. Clin Endocrinol (Oxf) 45:453-460 (1996).

Tanaka H, Perez MS, Powell M et al. Steroid 21-hydroxylase autoantibodies: measurements with a new immunoprecipitation assay. J Clin Endocrinol Metab 82:1440-1446 (1997).

The Finnish-German APECED Consortium. An autoimmune disease, APECED, caused by mutations in a novel gene featuring two PHD-type zinc-finger domains. Autoimmune Polyendocrinopathy-Candidiasis-Ectodermal Dystrophy. Nat Genet 17:399-403 (1997).

Tonacchera M, Ferrarini E, Dimida A, et al. Gonadotrophin receptor blocking antibodies measured by the use of cell lines stably expressing human gonadotrophin receptors are not detectable in women with 46,XX premature ovarian failure. Clin Endocrinol (Oxf) 61:376-381 (2004).

Tsigkou A, Marzotti S, Borges L, et al. High serum inhibin concentration discriminates autoimmune oophoritis from other forms of primary ovarian insufficiency. J.Clin.Endocrinol.Metab. 93:1263-1269 (2008).

Welt CK, Falorni A, Taylor AE, Martin KA, Hall JE. Selective theca cell dysfunction in autoimmune oophoritis results in multifollicular development, decreased estradiol, and elevated inhibin B levels. J Clin Endocrinol Metab 90:3069-3076 (2005).

Wheatcroft NJ, Salt C, Milford-Ward A, Cooke ID, Weetman AP. Identification of ovarian antibodies by immunofluorescence, enzyme-linked immunosorbent assay or immunoblotting in premature ovarian failure. Hum Reprod 12:2617-2622 (1997)

Winqvist O, Karlsson FA, Kämpe O. 21-Hydroxylase, a major autoantigen in idiopathic Addison's disease. Lancet 339:1559-1562 (1992).

Winqvist O, Gustafsson J, Rorsman F, Karlsson FA, Kämpe O. Two different cytochrome P450 enzymes are the adrenal antigens in autoimmune polyendocrine syndrome type I and Addison's disease. J Clin Invest 92:2377-2385 (1993).

Wuepper KD, Weigienka LC, Hugh Fudenberg H. Immunologic aspect of adrenocortical insufficiency. Am J Med 46:206-216 (1969). 
Yu L, Brewer KW, Gates S et al. DRB1*04 and DQ alleles: expression of 21-hydroxylase autoantibodies and risk of progression to Addison's disease. J Clin Endocrinol Metab 84:328-335 (1999).

Zelissen PM, Bast EJ, Croughs RJ. Associated autoimmunity in Addison's disease. J Autoimmunity 8:121-130 (1995). 


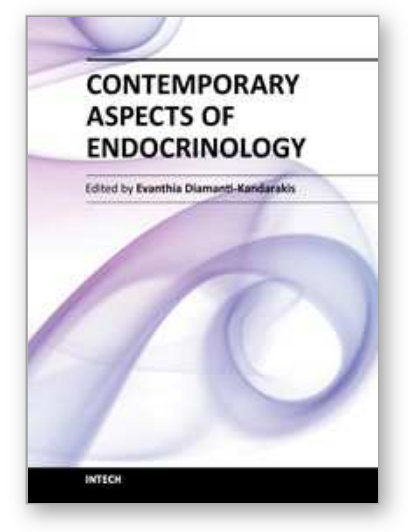

\author{
Contemporary Aspects of Endocrinology \\ Edited by Dr. Evanthia Diamanti-Kandarakis
}

ISBN 978-953-307-357-6

Hard cover, 454 pages

Publisher InTech

Published online 30, November, 2011

Published in print edition November, 2011

This book aims to provide readers with a general as well as an advanced overview of the key trends in endocrine disorders. While covering a variety of topics ranging from thyroid carcinogenesis and pituitary adenomas to adrenal tumors and metabolic bone disease, this book also focuses on more specific issues not yet fully elucidated (e.g. the molecular pathways involved in thyrotropin beta gene regulation or monogenic phosphate balance disorders). Readers of different fields and background will have the opportunity to update their knowledge and more importantly to clarify areas of uncertainty and controversies in several topics of endocrine disorders.

\title{
How to reference
}

In order to correctly reference this scholarly work, feel free to copy and paste the following:

Alberto Falorni and Stefania Marzotti (2011). Autoimmunity to Steroid-Producing Cells, Contemporary Aspects of Endocrinology, Dr. Evanthia Diamanti-Kandarakis (Ed.), ISBN: 978-953-307-357-6, InTech, Available from: http://www.intechopen.com/books/contemporary-aspects-of-endocrinology/autoimmunity-to-steroid-producingcells

\section{INTECH}

open science | open minds

\section{InTech Europe}

University Campus STeP Ri Slavka Krautzeka 83/A 51000 Rijeka, Croatia Phone: +385 (51) 770447

Fax: +385 (51) 686166 www.intechopen.com

\section{InTech China}

Unit 405, Office Block, Hotel Equatorial Shanghai No.65, Yan An Road (West), Shanghai, 200040, China 中国上海市延安西路65号上海国际贵都大饭店办公楼405单元 Phone: +86-21-62489820

Fax: +86-21-62489821 
(C) 2011 The Author(s). Licensee IntechOpen. This is an open access article distributed under the terms of the Creative Commons Attribution 3.0 License, which permits unrestricted use, distribution, and reproduction in any medium, provided the original work is properly cited. 